\title{
Optimization of coagulation-flocculation parameters using a photometric dispersion analyser
}

\author{
S. R. Ramphal and M. S. Sibiya \\ Rand Water, Process Technology Department, Glen Vista, South Africa \\ Correspondence to: S. R. Ramphal (sramphal@randwater.co.za)
}

Received: 30 December 2013 - Published in Drink. Water Eng. Sci. Discuss.: 6 February 2014

Revised: 19 May 2014 - Accepted: 25 June 2014 - Published: 23 July 2014

\begin{abstract}
The size and structural characteristics of floc particles are important design and control parameters in water treatment and should be rapidly monitored with a reasonable amount of accuracy. In this study, a photometric dispersion analyser (PDA) coupled to standard jar test experiments was used to optimize coagulationflocculation parameters while monitoring floc size and structure as well as the rate of floc formation during coagulation using alum. The optimal coagulation conditions were as follows: sample $\mathrm{pH} 8$; alum dosage, $3 \mathrm{mg} \mathrm{L}^{-1}$ as $\mathrm{Al}^{3+} ; G$ value, $172 \mathrm{~s}^{-1}$; rapid mixing time, $20 \mathrm{~s}$. These conditions resulted in unstable treated water having a calcium carbonate precipitation potential (CCPP) of $-15 \mathrm{mg} \mathrm{L}^{-1}$ as $\mathrm{CaCO}_{3}$ and required a slaked lime dosage of $17 \mathrm{mg} \mathrm{L}^{-1}$ as $\mathrm{CaCO}_{3}$ to equilibrate CCPP to acceptable levels. PDA data revealed that aggregation rate and steady-state variance are primary parameters as both have substantial influence on coagulation-flocculation efficiency. However, the average steady state ratio, although an important parameter, had a lessened impact on coagulation-flocculation efficiency. The results of this study showed that the PDA instrument is an important tool in coagulation kinetic studies and can be employed as an additional tool in the optimization of coagulation conditions.
\end{abstract}

\section{Introduction}

The treatability of a water source, including the determination of optimal conditions for specific parameters (most effective coagulant, dosage rates, $\mathrm{pH}$, velocity gradient and mixing time), is conventionally performed at bench-scale using standard jar test experiments. The performance of these experiments is generally determined through measuring turbidity and/or colour removal. Although this method of performance measure can provide sufficient information to permit pilot- or full-scale implementation, it does possess inherent limitations as it provides no information on floc particle size and structure.

The size distribution of floc particles is an important design and control parameter during coagulation-flocculation (Spicer et al., 1996). In combination with floc particle structure and density, the size distribution of floc particles is of great significance in solid-liquid separation processes such as sedimentation (Selomulya et al., 2001). Floc size and structure are influenced by several operational parameters and di- rectly impacts floc density which controls solid removal efficiency during sedimentation (Spicer and Pratsinis, 1996).

During coagulation-flocculation, both floc particle size and structure undergo transitional phases. Initially, upon coagulant dosage, there is a period of rapid floc growth in which the size and structure of the floc aggregates are dynamic in nature. This is followed by a steady- state region or equilibrium between particle growth and fragmentation for a specific period, during which, the floc particle size does not change. The shape of the particle size distribution curve is critical as it influences coagulation-flocculation kinetics, the rate of floc growth, floc characteristics and solid removal processes (Selomulya et al., 2001; Spicer et al., 1996). It is therefore very important to rapidly quantify both size and structure of aggregates to generate a particle size distribution curve with a reasonable amount of accuracy (Selomulya et al., 2001).

One of the most widely used techniques employed to determine aggregate structure and size distribution are light scattering techniques. These techniques are advantageous as 
Table 1. Raw water characteristics.

\begin{tabular}{lrrrr}
\hline Parameter & $\mathrm{pH}$ & $\begin{array}{r}\text { Turbidity } \\
(\mathrm{NTU})\end{array}$ & $\begin{array}{r}\mathrm{UV}_{300} \\
\left(\mathrm{~cm}^{-1}\right)\end{array}$ & $\begin{array}{r}\text { Temperature } \\
\left({ }^{\circ} \mathrm{C}\right)\end{array}$ \\
\hline Average & 7.93 & 55.57 & 0.4223 & 20 \\
\hline
\end{tabular}

they offer an estimation of a wide range of particle sizes in a rapid and non-destructive manner (Selomulya et al., 2001). A photometric dispersion analyser (PDA) has become an important instrument that has been widely used in monitoring coagulation-flocculation kinetics (Mixon et al., 2013; Ball et al., 2011; Staaks et al., 2011; Zoubolis and Tzoupanos, 2009, 2010; Xiao et al., 2009; Huang and Liu, 1996).

A PDA is a fibre-optical monitor which measures the fluctuation in the intensity of light transmitted through a flowing suspension (Huang and Liu; 1996). More specifically, it measures the root mean square of the fluctuating signal $\left(V_{\mathrm{rms}}\right)$ and the average transmitted light intensity $\left(d_{\mathrm{c}}\right)$. The ratio of $V_{\mathrm{rms}}$ to $d_{\mathrm{c}}$ is a valuable tool in coagulation-flocculation studies as it permits quantification of aggregation or disaggregation of the suspension to be monitored (Huang and Liu; 1996). This ratio can be derived as follows (Xiao et al., 2009):

Ratio $=\left(\frac{L}{A}\right)^{1 / 2}\left(\sum N_{i} C_{i}^{2}\right)^{1 / 2}$

where $L$ is the optical path length, $A$ is the effective cross sectional area of the light beam, $N_{i}$ is the number and concentration class of size class $i$ and $\mathrm{C}_{i}$ is particle scattering cross-section of size class $i$ respectively. The ratio values obtained from the PDA is affected only by $\left(\sum N_{i} C_{i}^{2}\right)^{1 / 2}$, and is almost entirely unaffected by contamination of the tube walls in the flow cell and by drift in electrical components (Xiao et al., 2009). This study is an extension of the one presented at the 12th edition of the International Conference on "Computing and Control for the Water Industry - CCWI 2013" (Ramphal and Sibiya, 2014). Similar to the CCWI 2013 study, this study used a PDA instrument to optimize coagulation conditions and monitor floc size and structure as well as the rate of floc formation using alum as a coagulant. Standard jar test experiments were performed concurrently with PDA experiments to determine the degree of particle destabilization. In addition, this study applied operational guidelines used at a large water utility in Africa for dosage optimization and assessed its impact on floc size and structure as well as the rate of aggregation. Further, the impact of alum dosage on the stability of treated water was also evaluated.

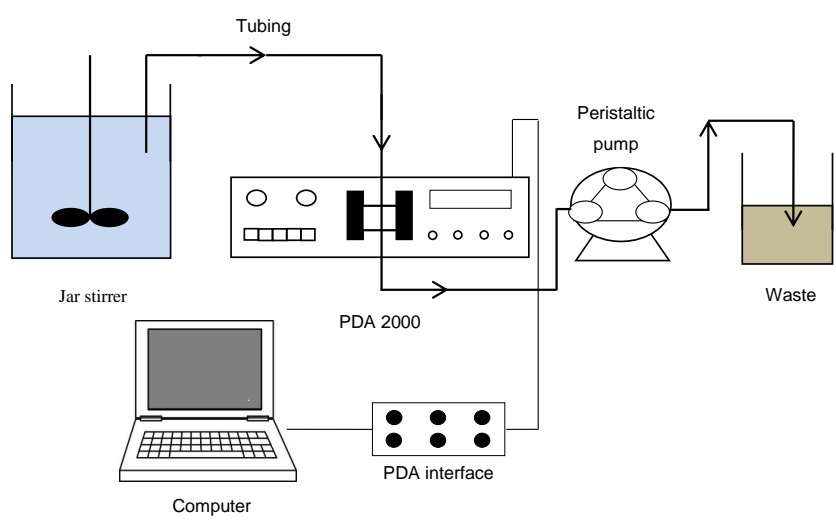

Figure 1. Experimental set up.

\section{Methodology}

\subsection{Jar tests}

Jar test experiments were performed on raw water obtained from the Vaal Dam (South Africa) (Table 1). Jar tests were carried out using a variable speed ZR 4-6 Jar tester (Zhongrun Water Industry Technology Development Co. Ltd, China) fitted with six flat paddle impellors. For each jar test the following procedure was performed: one litre of raw water was added to each Perspex jar; the $\mathrm{pH}$ of samples were adjusted to the relevant $\mathrm{pH}$ using either $0.1 \mathrm{M}$ hydrochloric acid or $0.1 \mathrm{M}$ sodium hydroxide; appropriate dosages of alum were dosed into each jar using plastic syringes; various velocity gradients were applied to the sample using electronically controlled programmes; upon completion of electronically controlled programme samples were left to settle for $15.5 \mathrm{~min}$.

\subsection{Instrumentation}

\subsubsection{Photometric dispersion analyser}

Coagulation-flocculation kinetics was determined using the PDA 2000 (Rank Brothers, England). Clear plastic tubing of $3 \mathrm{~mm}$ in diameter was used to transport samples from the jar to the fibre optic probes at a flow rate of $22 \mathrm{~mL} \mathrm{~min}^{-1}$. Sample flow rate was controlled by a peristaltic pump which was placed after the PDA instrument to prevent floc breakage prior to analysis (Fig. 1). To ensure comparison of PDA experiments, the direct current (DC) output of source water was maintained at a constant voltage by adjusting the DC gains on the instrument. For all experiments, the limit and filter modes were used as this reduced the effects of large particles and air bubbles and increased the averaging time to obtain smoother output values, respectively. All data was recorded using an ADC-20 data-logger coupled to the Picolog Software. 
Mixing intensity

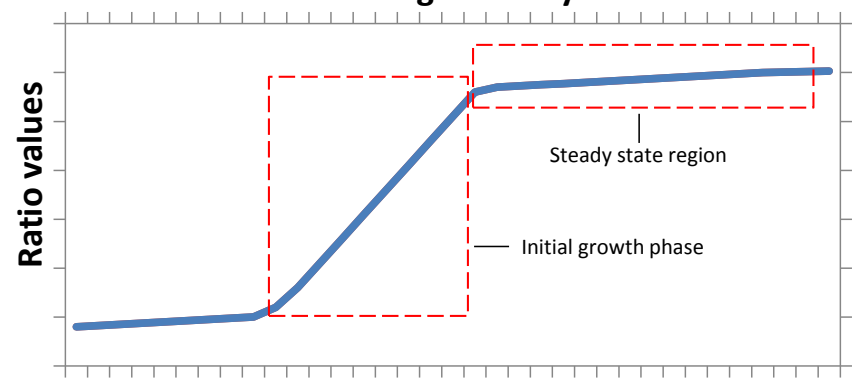

Time

Figure 2. Time dependent ratio curve.

\subsubsection{Other instrumentation}

A HACH 2100Q turbidimeter and a Cary 50-Conc Varian UV-Vis Spectrophotometer was used to measure turbidity and $\mathrm{UV}_{300}$ values respectively. $\mathrm{UV}_{300}$ was used a measure of non-visible colour and is hereby referred to as colour. The temperature and $\mathrm{pH}$ were measured using a Metrohm $692 \mathrm{pH} /$ ion meter. All titrations were performed using a Schott Titronic 96 auto-titrator while the conductivity was measured using a Labotec 197i conductivity meter.

\subsection{Analysis of PDA data}

The time dependent ratio values collected during each coagulation-flocculation experiment generated a ratio curve of similar pattern (Fig. 2). Figure 2 shows that there are two distinct regions with each indicating the evolution of aggregate size with time at various shear rates (Selomulya et al., 2001). In the initial growth region, fluid shear promotes particle collision which results in aggregate growth. As these aggregates grow, breakage becomes a more significant factor as the size range of the aggregate is more susceptible to fragmentation by turbulent eddies. This results in the attainment of steady-state region. During this phase, due to the attainment of a dynamic equilibrium between aggregate growth and aggregate fragmentation, aggregates are of equal size, since ratio values remain constant over time (Hopkins and Ducoste, 2003; Spicer and Pratsinis, 1996; Oles, 1992).

In this study, three calculations were used to analyse the data obtained during the coagulation-flocculation experiments. These calculations included the aggregation rate during rapid mixing, time-weighted average steady-state ratio and time-weighted steady-state variance as described by Mixon et al. (2013); Staaks et al. (2011); Xiao et al. (2009) and Hopkins and Ducoste (2003). The aggregation rate (AR) during coagulation was calculated by:

$\mathrm{AR}=\frac{\text { Ratio }_{i}-\text { Ratio }_{0}}{\text { time }_{i}}$

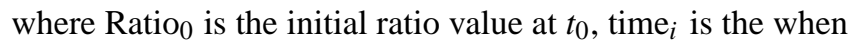
the PDA output reaches its maximum value of Ratio $i$. In accordance to work performed by Staaks et al. (2011), initial calculations determined the aggregation rate of the first minute, first to fifth minute and the entire first five minutes. It was found that the aggregation rate for the first minute yielded the best results; hence, this parameter was used for the rest of the study. The time-weighted average steady-state ratio was determined by:

$\overline{\text { ratio }}=\frac{\sum_{i=1}^{N}\left(\text { ratio }_{i} \times \text { time }_{i}\right)}{\sum_{i=1}^{N} \text { time }_{i}}$

Equation (3) represents the state of aggregation during the steady state period of coagulation-flocculation. The final calculation used in this study was the time-weighted steadystate variance, which was also computed using the data from the steady state period during coagulation-flocculation as follows:

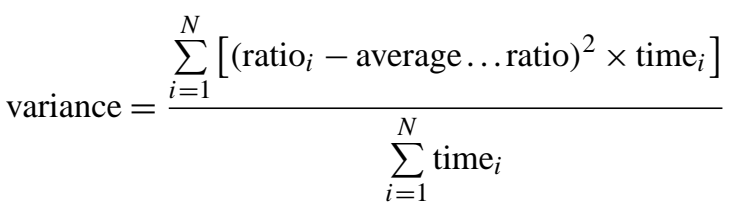

Equation (4) was used as a measure of floc size and structural differences. According to Hopkins and Ducoste (2003), smaller variance is indicative of a tighter floc size distribution and a more homogenous, dense and less porous floc structure.

\subsection{Assessment of calcium carbonate precipitation potential}

The stability of treated water was determined by measuring the calcium carbonate precipitation potential (CCPP) of specific samples. The CCPP was determined using the Stasoft $4^{\odot}$ software (version 4) which is a tool for designing, modelling and controlling water treatment processes that involve calcium carbonate chemistry. To measure the CCPP, specific water quality parameters, inclusive of temperature, conductivity, dissolved calcium, $\mathrm{pH}$ and total alkalinity were determined.

\section{Results and discussion}

\subsection{Optimization of $\mathrm{pH}$}

Jar test experiments were performed to assess turbidity and colour removal as well as coagulation-flocculation kinetics at various $\mathrm{pH}$ values. This was achieved by adding a constant alum dosage of $10 \mathrm{mg} \mathrm{L}^{-1}$ as $\mathrm{Al}^{3+}$ to samples adjusted to $\mathrm{pH}$ 6-9. According to Pernitsky and Edzwald (2006), favourable $\mathrm{pH}$ conditions for alum coagulation generally occur between 
(a)

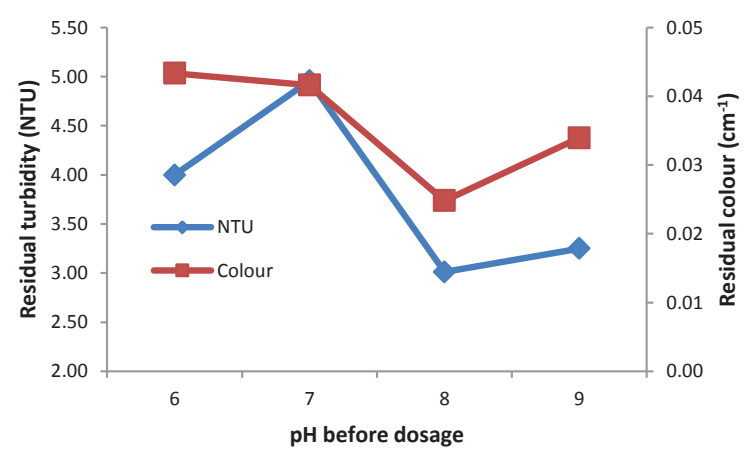

(c)

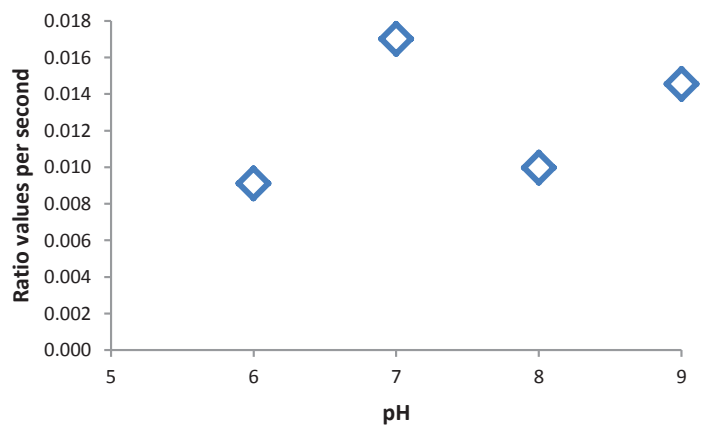

(b)

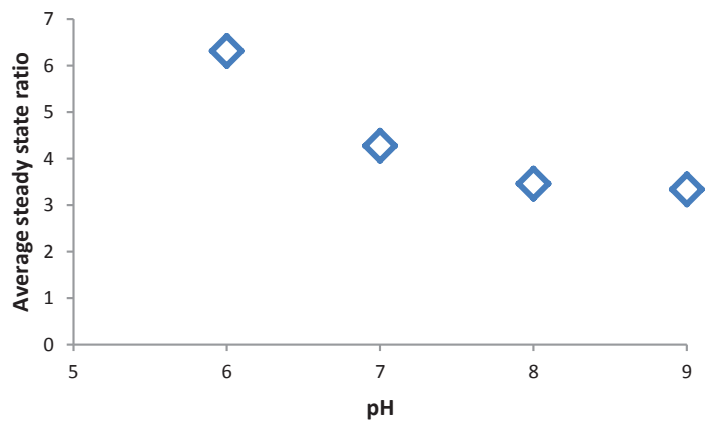

(d)

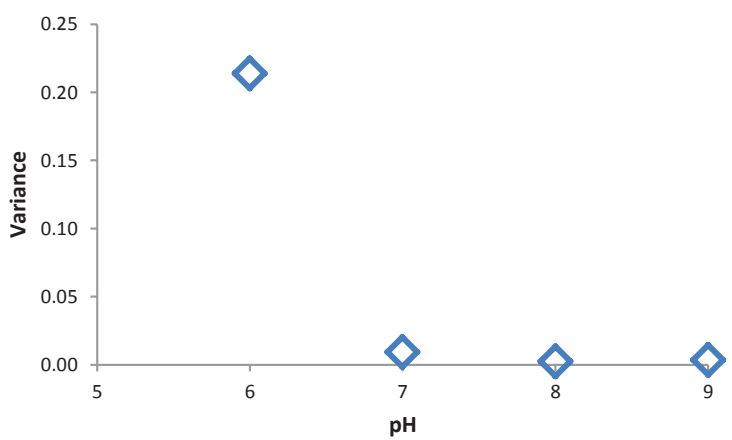

Figure 3. Optimization of $\mathrm{pH}$ - (a) residual turbidity and colour; (b) average steady-state ratio; (c) aggregation rate; (d) steady-state variance.

a $\mathrm{pH}$ of $6-7$. Figure $3 \mathrm{a}$ indicates that the lowest residual turbidity and colour was observed at an initial sample $\mathrm{pH}$ of 8 ; corresponding to a coagulation $\mathrm{pH}$ of 6.29 .

The optimal $\mathrm{pH}$ also coincided with the minimal solubility of alum, indicating that sweep flocculation is the primary coagulation mechanism through the formation of aluminium hydroxide precipitates (Pernitsky and Edzwald, 2006; Gregor et al., 1997). One would expect that the largest floc size would correspond to highest coagulation efficiency; in other words, the largest floc size and floc growth rate should result in the lowest residual turbidity and colour. However, this was not observed as the lowest residual turbidity and colour (Fig. 3a) corresponded to the lowest average steady state ratio and aggregation rate (Fig. $3 \mathrm{~b}$ and c). Further, from Fig. 4b, one can see that at the optimal coagulation $\mathrm{pH}$ of 6.29 , sweep flocculation should be the primary coagulation mechanism; hence, one can expect the largest floc sizes to form under these conditions. However, from Fig. 3b, a trend of increasing ratio values was observed with decreasing $\mathrm{pH}$, which according to Fig. 4a should shift the aluminium hydrolysis species to ionic forms. This strongly suggests the presence of interfering contaminants within the source water.

Figure $3 \mathrm{~d}$ shows that the lowest steady-state variance was obtained at a $\mathrm{pH}$ of 8 . According to Mixon et al. (2013) and Hopkins and Ducoste (2003), low steady-state variance values indicates the existence of a narrow range of floc sizes and stronger flocs at a particular location. This can be expected as the coagulation $\mathrm{pH}$ corresponds to the minimum solubility, indicating the presence of solid aluminium hydroxide precipitates. In contrast, an initial sample $\mathrm{pH}$ of 6 displayed the highest steady-state variance, indicating the occurrence of a wide range of floc sizes and placing further significance on the existence of interfering contaminants within the source water. Although there was a lack of correspondence between residual and PDA data, the residual data provided sufficient evidence to indicate that an initial sample $\mathrm{pH}$ of 8 was optimal. This sample $\mathrm{pH}$ was used for the rest of the study.

\subsection{Optimization of dosage}

The optimization of alum dosage was performed by adjusting sample $\mathrm{pH}$ to 8 while varying the alum dosage from $2-12 \mathrm{mg} \mathrm{L}^{-1}$ as $\mathrm{Al}^{3+}$. Figure 5a indicates that an alum dosage of $6 \mathrm{mg} \mathrm{L}^{-1}$ as $\mathrm{Al}^{3+}$ resulted in the lowest residual turbidity and colour. This dosage reduced the $\mathrm{pH}$ from 8 to 6.69 which favoured sweep flocculation through the formation of aluminium hydroxide precipitates (Srinivasan et al., 1999). Further, the isoelectric point of alum occurs at $\mathrm{pH} 8$ indicating that $\mathrm{pH}$ values less than 8 yield positively charged precipitates, which are able to neutralize the negatively charged particles in the water sample (Gregory and Duan, 2001). 
(a)

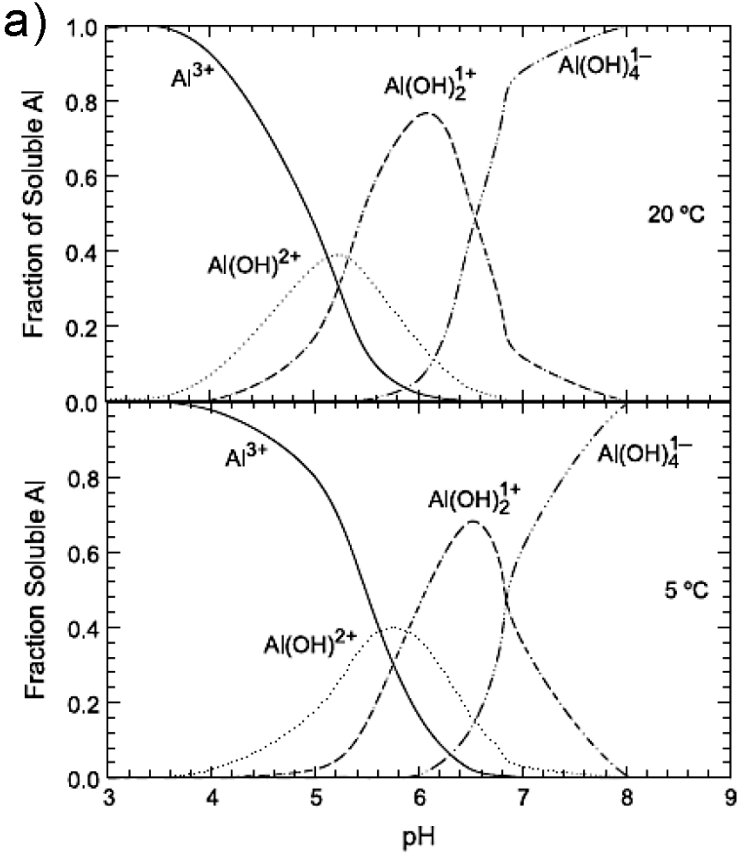

(b)

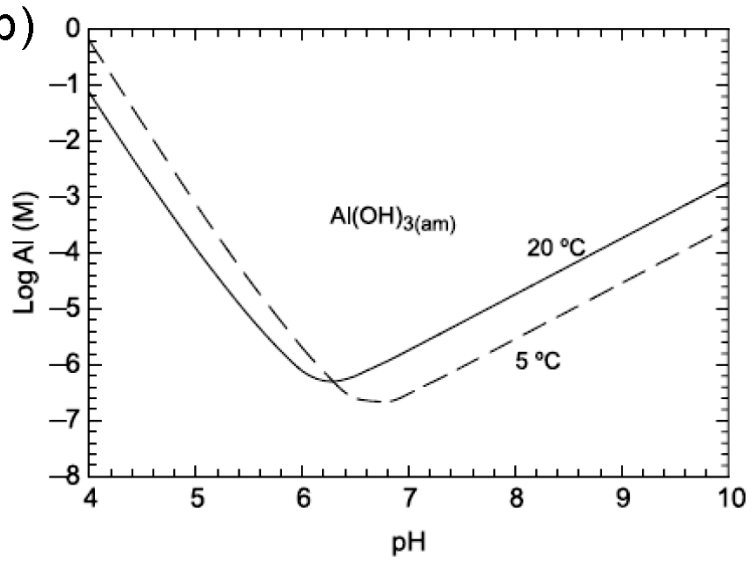

Figure 4. Distribution of aluminium hydrolysis products; (a) dissolved species; (b) amorphous precipitate (adapted from Pernitsky and Edzwald, 2006).
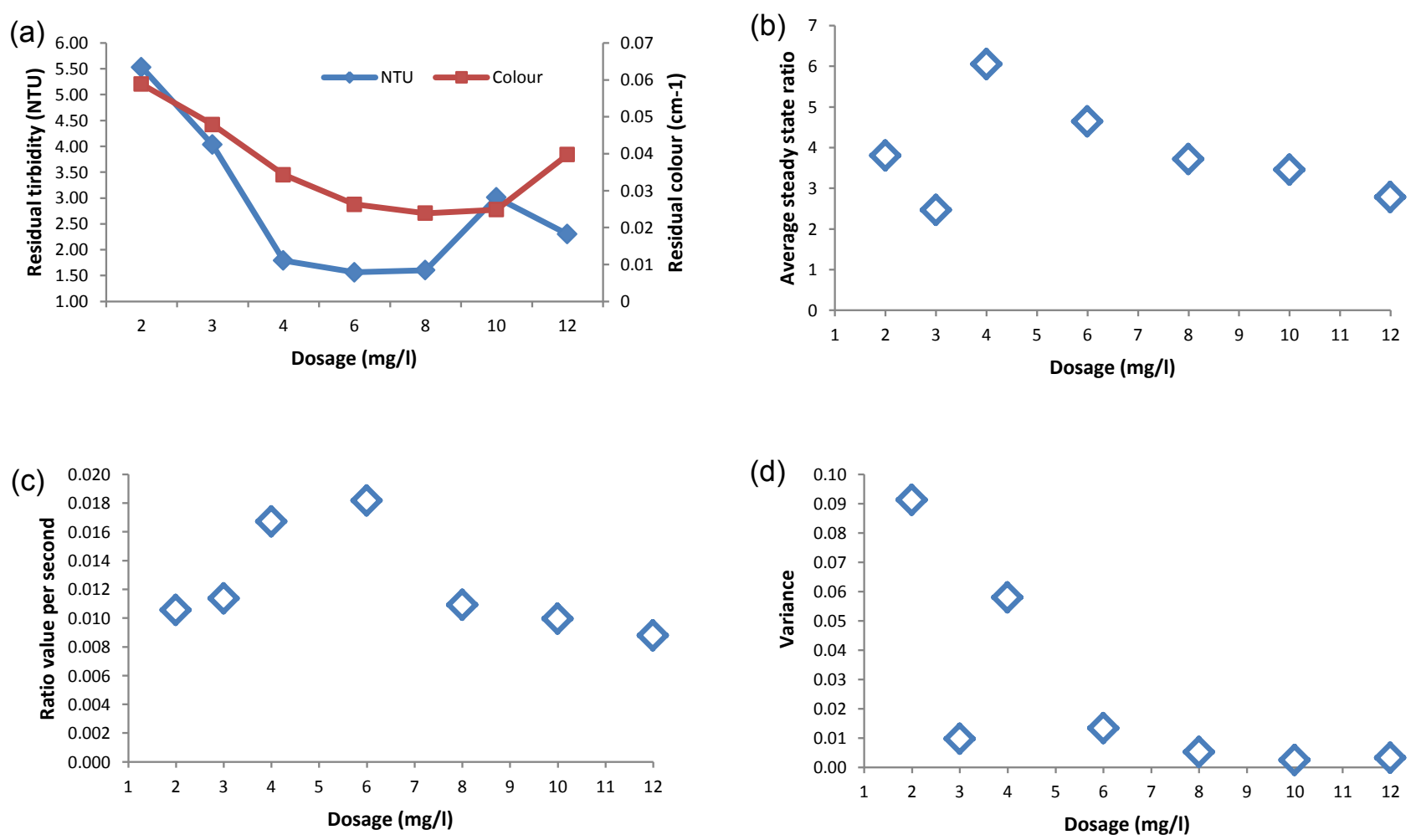

Figure 5. Optimization of dosage - (a) residual turbidity and colour; (b) average steady-state ratio; (c) aggregation rate; (d) steady-state variance. 
(a)

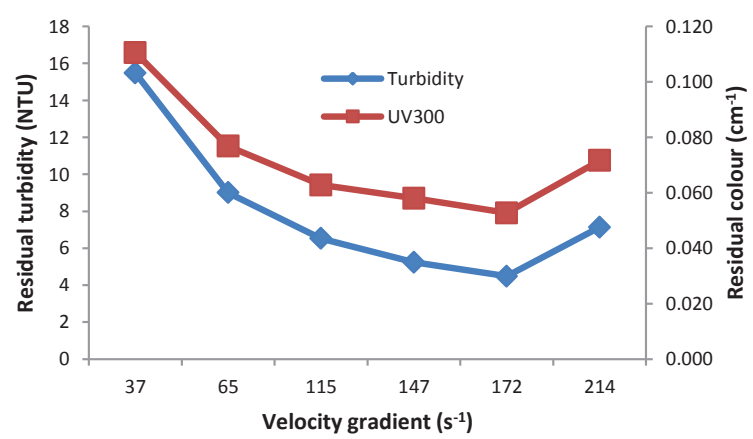

(c)

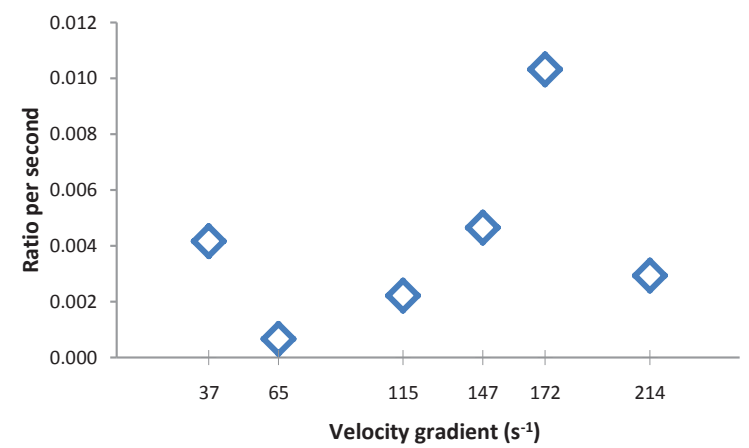

(b)

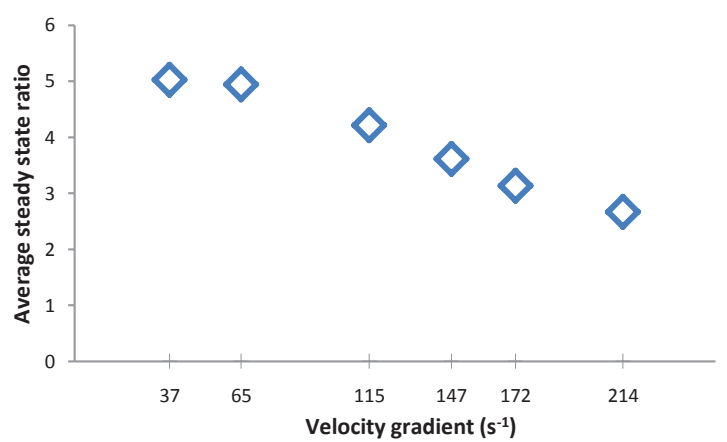

(d)

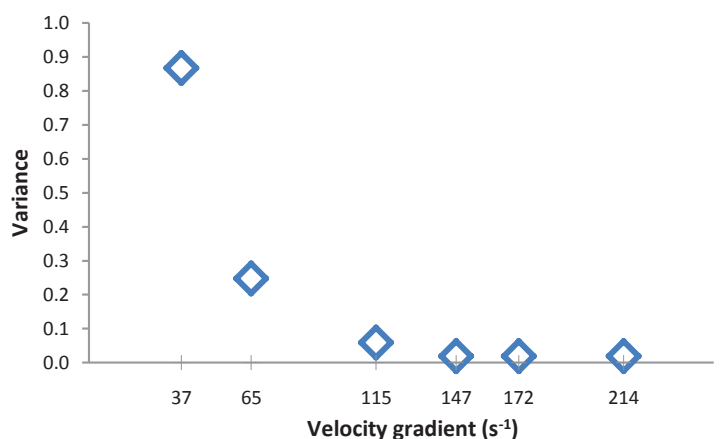

Figure 6. Optimization of velocity gradient - (a) residual turbidity and colour; (b) Average steady-state ratio; (c) aggregation rate; (d) steady-state variance.

Figure $5 \mathrm{~b}$ shows that the largest average steady-state ratios were obtained for alum dosages of 4 and $6 \mathrm{mg} \mathrm{L}^{-1}$ as $\mathrm{Al}^{3+}$. Although an alum dosage of $6 \mathrm{mg} \mathrm{L}^{-1}$ as $\mathrm{Al}^{3+}$ did not represent the largest average steady-state ratio value, it displayed the highest efficiency in terms of turbidity and colour removal. This indicates that floc size, although important in coagulation-flocculation processes, is not the most important parameter. Figure $5 \mathrm{c}$ and $\mathrm{d}$ show that an alum dosage of $6 \mathrm{mg} \mathrm{L}^{-1}$ as $\mathrm{Al}^{3+}$ displayed a higher aggregation rate and lower steady-state variance to that of $4 \mathrm{mg} \mathrm{L}^{-1}$ as $\mathrm{Al}^{3+}$ dosage. This indicates that an alum dosage of $6 \mathrm{mg} \mathrm{L}^{-1}$ as $\mathrm{Al}^{3+}$ resulted in a higher floc growth rate and that the flocs size displayed greater degree of strength and floc size homogeneity. Based on these results, it is possible that these two parameters contributed to the enhanced performance of the $6 \mathrm{mg} \mathrm{L}^{-1}$ as $\mathrm{Al}^{3+}$ alum dosage and may possibly be primary parameters for consideration in coagulation-flocculation kinetic studies.

However, at a large water utility in Africa, to reduce chemical costs, an operational guideline using the lowest coagulant dosage which yielded a post-sedimentation turbidity of less than $5 \mathrm{NTU}$ is applied. Under these circumstances, an alum dosage of $3 \mathrm{mg} \mathrm{L}^{-1}$ of $\mathrm{Al}^{3+}$ was optimal. This dosage displayed inferior PDA data to that of the $6 \mathrm{mg} \mathrm{L}^{-1}$ as $\mathrm{Al}^{3+}$ dosage as it presented the lowest average-steady ratio and aggregation rate values signifying the presence of smaller floc particles formed at moderate rate. However, it did exhibit a lower steady-state variance value, indicating that floc particle sizes were more homogenous, denser and less porous in nature. A dosage of $3 \mathrm{mg} \mathrm{L}^{-1}$ of $\mathrm{Al}^{3+}$ was used for subsequent experiments.

\subsection{Optimization of velocity gradient}

In this experiment, the rapid mixing intensity was varied while applying the optimal alum dosage of $3 \mathrm{mg} \mathrm{L}^{-1}$ as $\mathrm{Al}^{3+}$ and initial sample $\mathrm{pH}$ of 8 . Figure 6a shows that the lowest residual turbidity and colour was obtained during application of a $G$ value of $172 \mathrm{~s}^{-1}$. At this velocity gradient, an optimal level of energy was dissipated which warranted efficient coagulation through the instantaneous and even distribution of alum (Degremont, 2007). It may seem appropriate to use high $G$ values during rapid mixing to maximise efficient use of a coagulant; however, each application has an upper limit (Bratby, 2006). Once $G$ values exceed this limit, there is a delay in floc formation and size.

This trend can be observed in Fig. $6 \mathrm{~b}$ and $\mathrm{c}$ in which the average steady state ratio and aggregation rate peaked at a specific $G$ value; with further increases in $G$ values resulting in lower values. This occurred as higher energy dissipation increases the shear rate and the number of particle collisions; hence, increasing the rate of floc break-up (Selomulya 
(a)

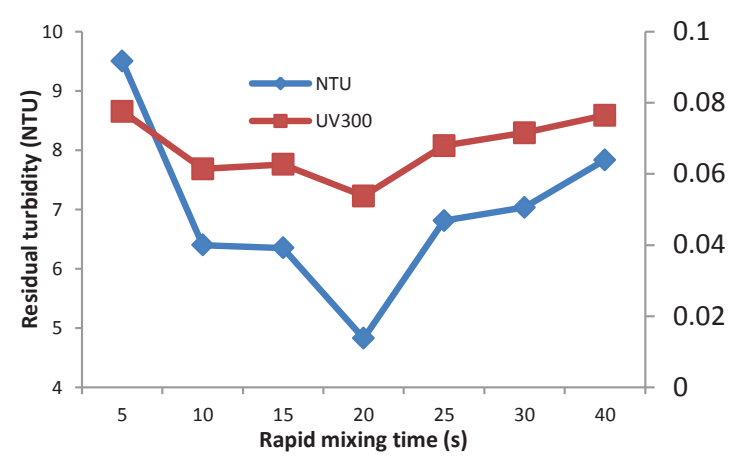

(c)

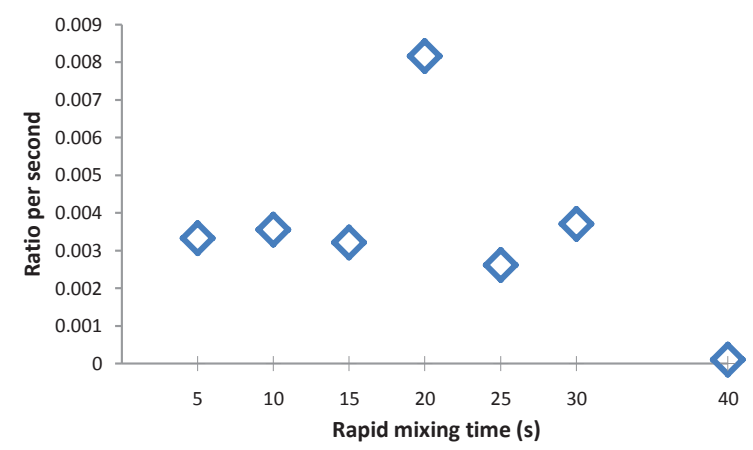

(b)

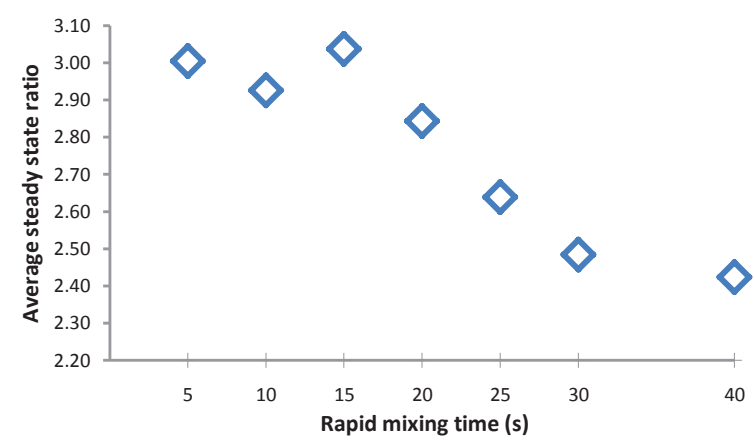

(d)

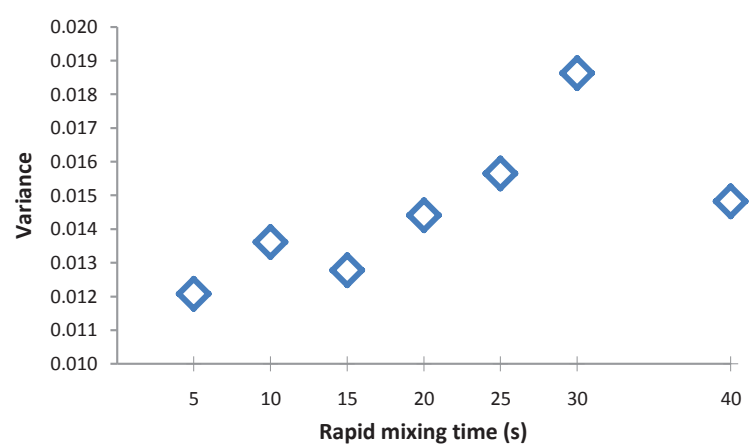

Figure 7. Optimization of rapid mixing time - (a) residual turbidity and colour; (b) average steady-state ratio; (c) aggregation rate; (d) steady-state variance.

et al., 2001). This resulted in the formation of smaller; denser and less porous aggregates which are structurally tolerant to higher shear forces, leading to a lower steady state mean floc size attained in a shorter period of time (Hopkins and Ducoste, 2003; Spicer and Pratsinis, 2001, Oles, 1992). This trend has been observed by various researchers (Hopkins and Ducoste, 2003; Selomulya et al., 2001; Spicer and Pratsinis, 1996).

Figure $6 \mathrm{~d}$ shows that the steady-state variance was substantially higher at lower velocity gradients $\left(\leq 115 \mathrm{~s}^{-1}\right)$. Mixon et al. (2013) and Hopkins and Ducoste (2003) explained that high steady-state variance at lower $G$ values was due to larger aggregates being sheared due to settling into the impellor region. Further, in this study, it was observed that as the $G$ value increased, the steady-state variance decreased. This indicates that at higher shear rates, the formation of a more homogenous floc suspension was favoured (Mixon et al., 2013). As observed in prior experiments, the largest average steady-state ratio obtained at a velocity gradient of $37 \mathrm{~s}^{-1}$ did not result in the highest efficiency in terms of turbidity and colour removal. Rather, a velocity gradient of $172 \mathrm{~s}^{-1}$ displayed the highest efficiency as it exhibited the highest aggregation rate and lowest steady-state variance when compared to other velocity gradients. A velocity gradient of $172 \mathrm{~s}^{-1}$ was used for the rest of the study.

\subsection{Optimization of rapid mixing time}

For this phase of the study, rapid mixing time was varied while applying the optimal alum dosage of $3 \mathrm{mg} \mathrm{L}^{-1}$ as $\mathrm{Al}^{3+}$, sample $\mathrm{pH}$ of 8 and a $G$ value $172 \mathrm{~s}^{-1}$. Figure 7 a shows that the lowest residual turbidity and colour was obtained when a rapid mixing time of $20 \mathrm{~s}$ was applied. This signifies that a velocity gradient of $172 \mathrm{~s}^{-1}$ was applied for an optimal period to ensure efficient coagulation through the instantaneous and even distribution of alum.

Similar to rapid mixing intensity, it may be desirable to apply an optimal velocity gradient for an extended period of time to maximise efficient use of coagulants. However, according to Bratby (2006), extended periods of rapid mixing may give rise to deleterious effects in the coagulationflocculation process. As such, each application will have an optimal rapid mixing time which is dependent on the rapid mixing intensity and coagulant concentration. The negative effect of prolonged rapid mixing time can be seen in Fig. 7a as higher residual turbidity and colour values were obtained during longer rapid mixing times.

Figure $7 \mathrm{~b}$ shows that the average steady state ratio values gradually decrease with increasing rapid mixing times. This was anticipated as prolonged rapid mixing times will expose aggregates to shear rates for longer periods of time. This will delay the floc growth process and allow for a longer period of particle collision; increasing the rate of floc breakup. 


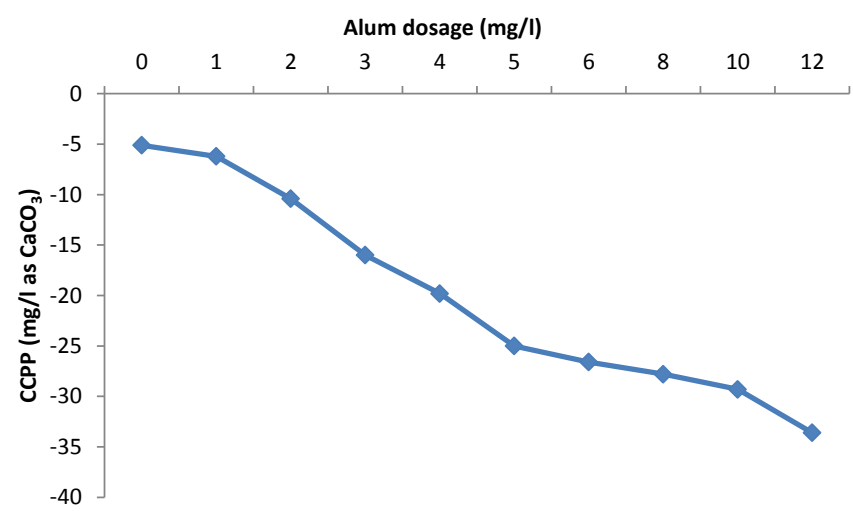

Figure 8. Impact of alum dosage on CCPP of treated water.

Selomulya et al. (2001) explained that higher circulation times reduces the time aggregates have to form larger sizes due to high shear stress, hence, a decrease in average steadystate ratio was observed.

In line with observations from previous experiments, the highest average steady-state ratio value, obtained from a rapid mixing time of $15 \mathrm{~s}$, did not result in the highest coagulation-flocculation performance in terms of turbidity and colour removal. Rather, a rapid mixing time of 20 s displayed the highest removal efficiency. PDA data represented in Fig. 7c and d indicate that a rapid mixing time of $20 \mathrm{~s}$ produced a higher aggregation rate and lower steady-state variance than that of $15 \mathrm{~s}$. This places further significance on the importance of the aggregation rate and steady-state variance in coagulation-flocculation studies. A rapid mixing time of $20 \mathrm{~s}$ was used for subsequent experiments.

\subsection{Impact of alum dosage on CCPP}

The impact of alum dosage on CCPP was investigated at an alum dosage range of $2-4 \mathrm{mg} \mathrm{L}^{-1}$ as $\mathrm{Al}^{3+}$, sample $\mathrm{pH}$ of 8; $G$ value of $172 \mathrm{~s}^{-1}$ and rapid mixing time of $20 \mathrm{~s}$. Figure 8 shows that the CCPP of treated water decreased with increasing alum dosage. To ensure stability of treated water, the production specification for CCPP at a large water utility is -2 to $+3 \mathrm{mg} \mathrm{L}^{-1}$ as $\mathrm{CaCO}_{3}$. However, Fig. 9 indicates that at an alum dosage range of $2-4 \mathrm{mg} \mathrm{L}^{-1}$ as $\mathrm{Al}^{3+}$ and a sample $\mathrm{pH}$ of 8 , the coagulation, flocculation and sedimentation process reduces the CCPP to -10.4 to -19.8 as $\mathrm{m} \mathrm{L}^{-1}$ as $\mathrm{CaCO}_{3}$, respectively. These values demonstrate the corrosive nature of treated water and a high probability of damage to infrastructure occurring. As a result, it is imperative that water treated with alum is stabilized using appropriate processes.

Lime is used widely during potable water treatment as a coagulant, to adjust coagulation $\mathrm{pH}$ or for stabilization of treated water. As a result, this study used slaked lime to equilibrate the CCPP of treated water. Figure 9 illustrates that three experiments were performed to optimise the slaked

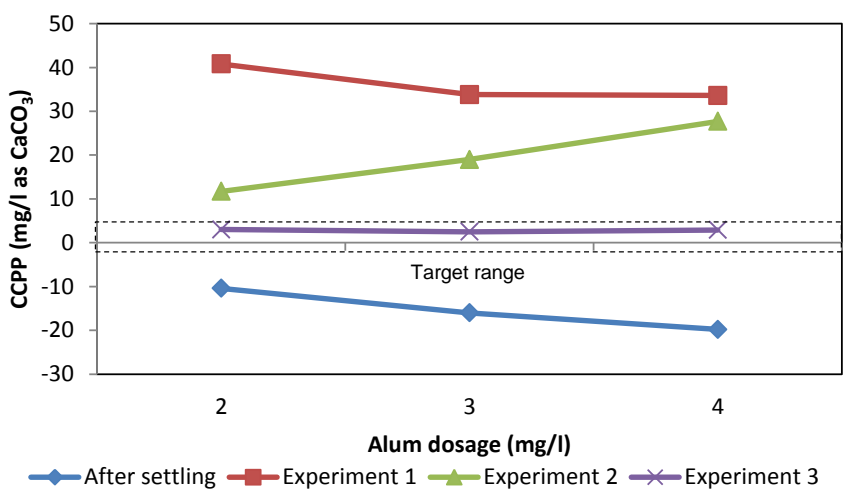

Figure 9. Equilibration of CCPP.

lime dosage required to increase the CCPP of treated water to $+3.0 \mathrm{mg} \mathrm{L}^{-1}$ as $\mathrm{CaCO}_{3}$. Experiment 3 demonstrates that for alum dosages of 2,3 and $4 \mathrm{mg} \mathrm{L}^{-1}$ as $\mathrm{Al}^{3+}$, the CCPP was adjusted to $3,2.5$ and $2.9 \mathrm{mg} \mathrm{L}^{-1}$ as $\mathrm{CaCO}_{3}$, respectively. This corresponded to slaked lime dosages of 13, 17 and $23 \mathrm{mg} \mathrm{L}^{-1}$ for alum dosages of 2,3 and $4 \mathrm{mg} \mathrm{L}^{-1}$, respectively.

\subsection{Impact of dosage sequence}

This experiment was performed to assess the effect of dosing slaked lime on water quality during coagulation, as well as the sequence of chemical dosage on the turbidity of settled water. It should be reiterated that slaked lime was used primarily for $\mathrm{pH} / \mathrm{CCPP}$ adjustment in this study. Two experimental scenarios were performed:

\section{Alum dosed first, followed by slaked lime}

\section{Slaked lime dosed first, followed by alum}

Figure 10a and $\mathrm{b}$ show that lower residual turbidity and colour levels were obtained when slaked lime was dosed before alum. Additionally, one should note that under both experimental scenarios, both turbidity and colour removals were enhanced at higher slaked lime dosages. As such, it appears that slaked lime functions as a coagulant chemical in addition to a $\mathrm{pH}$ adjustment chemical.

To gain further understanding on the coagulationflocculation kinetics, samples from both experimental scenarios were passed through the PDA monitor. When alum was dosed first, the ratio output values were very low and did not produce a ratio profile as shown in Fig. 2. As a result, the root mean square (RMS) gain on the instrument was adjusted accordingly to amplify the signal. These instrumental settings were kept constant for both experimental scenarios to allow for data comparison. However, in the case of experimental scenario two (lime addition first); the amplified instrumental settings resulted in a ratio overload during the steady-state growth region. A ratio overload occurs when the 

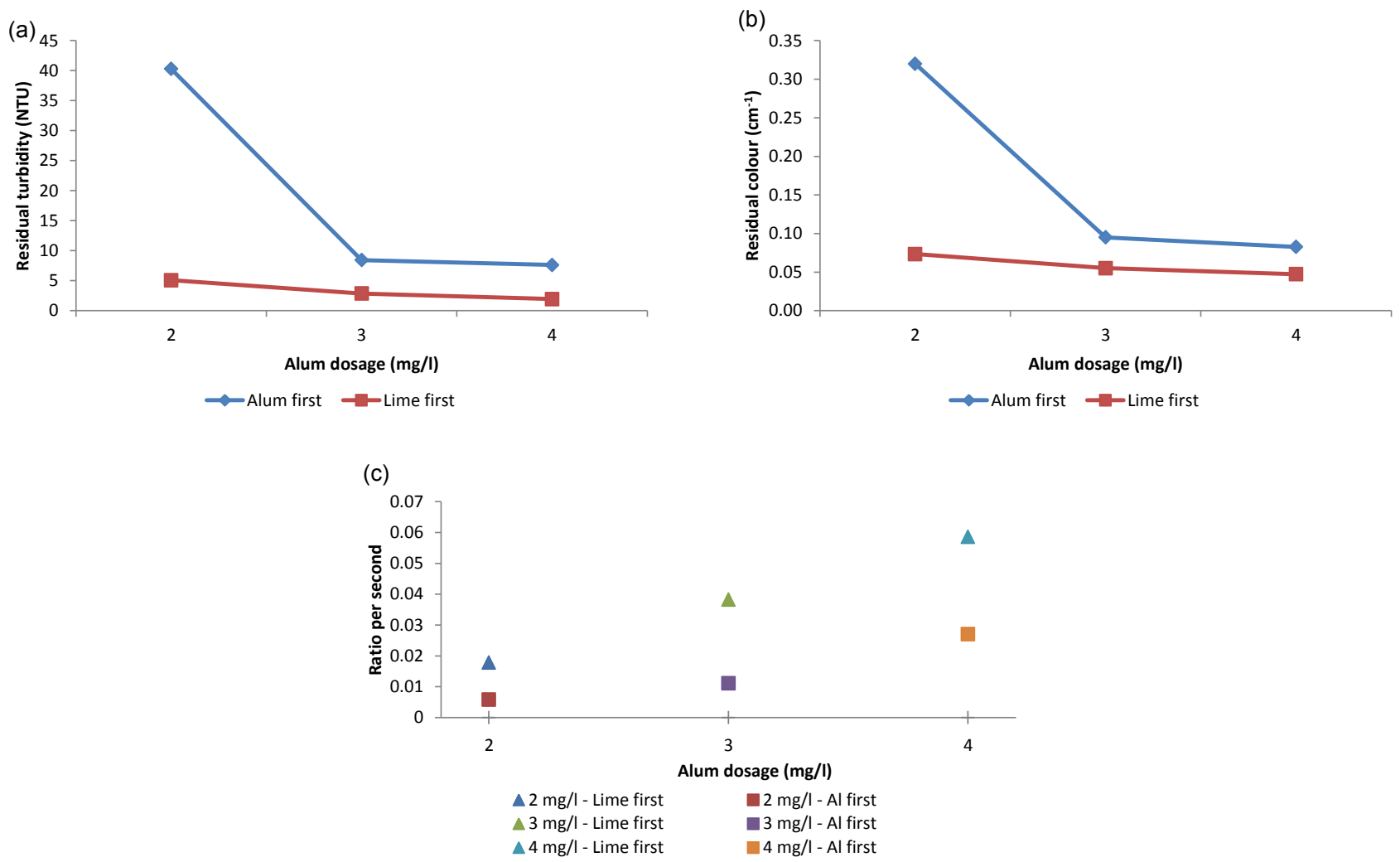

Figure 10. Impact of dosage sequence; (a) residual turbidity; (b) residual colour; (c) aggregation rate.

RMS output is greater than the DC output and can be corrected by reducing the RMS gain. However, this was not possible as any decrease in the RMS gain would have resulted in a loss of the ratio profile of experimental scenario one (alum addition first). As a consequence, this prevented the comparison of PDA data obtained during the steady-state, namely the average steady-state ratio and the steady-state variance. However, it did permit the comparison of the aggregation rates, as during this time the RMS output was less than DC output; hence, the ratio overload signal was not activated.

Figure 10c indicates that the addition of lime first resulted in a higher aggregation rate at the dosage levels investigated. These superior aggregation rates may have been contributing factors to the improved coagulation-flocculation efficiency of adding slaked lime first as shown by the lower residual turbidity and colour levels in Fig. 10a and b.

\section{Conclusions}

This study used a PDA to optimize coagulation conditions and monitor floc size and structure as well as floc growth rate during coagulation-flocculation using alum. The results of this study indicate that optimal coagulation-flocculation conditions were as follows: sample $\mathrm{pH}$ of 8 , alum dosage of $3 \mathrm{mg} \mathrm{L}^{-1}$ as $\mathrm{Al}^{3+}$, rapid mixing intensity of $172 \mathrm{~s}^{-1}$ and rapid mixing time of $20 \mathrm{~s}$. Additional PDA parameters, namely, the aggregation rate, average steady-state ratio and steady-state variance were generated using PDA ratio data to gain further understanding of the coagulation-flocculation process.

The derived PDA data revealed that in all optimization experiments, the average steady-state ratio, although an important parameter, was a secondary parameter as it has a lessened impact on coagulation-flocculation efficiency. It was found that the aggregation rate and steady-state variance were more suitable parameters to assess coagulationflocculation performance as they had direct significance on coagulation-flocculation efficiency. These parameters may be seen as primary kinetic parameters and should be given greater attention during coagulation-flocculation studies. The results of this study showed that the PDA instrument is an important tool in coagulation kinetic studies and can be employed as an additional tool in the optimization of coagulation conditions. 
Acknowledgements. The authors would like to express gratitude towards both the Experimental Facility at the Process Technology Department as well as the Analytical Services Department at Rand Water for their role in this project.

Edited by: S. Meniconi

\section{References}

Ball, T., Carriere, A., and Barbeau, B.: Comparison of two online flocculation monitoring techniques for predicting turbidity removal by granular media filtration, Environ. Technol., 32, 10951105, 2011.

Bratby, J.: Coagulation and flocculation in water and wastewater treatment, 2nd Edn., IWA Publishing, London, United Kingdom, 2006.

Degremont: Water treatment handbook, 7th Edn., Lavoisier SAS, France, 2007.

Gregor, J. E., Nokes, C. J., and Fenton, E.: Optimizing natural organic matter removal from low turbidity waters by controlled pH adjustment of aluminium coagulation, Water Res., 31, 29492958, 1997.

Gregory, J. and Duan, J.: Coagulation by hydrolyzing metal salts, Pure Appl. Chem., 73, 2017-2026, 2001.

Hopkins, D. C. and Ducoste, J. J.: Characterizing flocculation under heterogeneous turbulence, J. Colloid Interf. Sci., 264, 184-194, 2003.

Huang, C. and Liu, C.: Automatic control for chemical dosing in laboratory scale coagulation process by using an optical monitor, Water Res., 30, 1924-1929, 1996.

Mixon, M., Staak, C., Fabris, R., Vimonses, V., Chow, C. W. K., Panglisch, S., van Leeuwen, J., and Drikas, M.: The impact of optimized coagulation on fouling for coagulation/ultrafiltration process, Desalin. Water Treat., 51, 2718-2725, 2013.

Oles, V.: Shear induced aggregation and break up of polystyrene latex particles, J. Colloid Interf. Sci., 154, 351-358, 1992.
Pernitsky, D. J. and Edzwald, J. K.: Selection of alum and polyaluminium coagulants: principles and applications, J. Water Supply Res. T., 55, 121-141, 2006.

Ramphal, S. and Sibiya, S. M.: Optimization of time requirement for rapid mixing during coagulation using a photometric dispersion analyzer, Proc., 12th Int. Conf. on "Computing and Control for the Water Industry - CCWI2013”, Perugia, Elsevier, Proc. Engin., 70, 1401-1410, 2014.

Selomulya, C., Amal, R., Bushell, G., and Waite, T. D.: Evidence of shear rate dependence on restructuring and breakup of latex aggregates, J. Colloid Interf. Sci., 236, 67-77, 2001.

Spicer, P. T. and Pratsinis, S. E.: Shear induced flocculation: The Evolution of Floc Structure and Size Distribution during ShearInduced Flocculation, Water Res, 30, 1049-1056, 1996.

Spicer, P. T., Pratsinis, S. E., and Trennepohl, M. D.: Coagulation and fragmentation: The variation of shear rate and the time lag for attainment of steady state, Ind. Eng. Chem. Res., 35, 30743080, 1996.

Srinivasan, P. T., Viraraghavan, T., and Subramanian, K. S.: Aluminium in drinking water: An overview, Water SA, 25, 47-55, 1999.

Staaks, C., Fabris, R., Lowe, T., Chow, C. W. K., van Leeuwen, J. A., and Drikas, M.: Coagulation assessment and optimization with a photometric dispersion analyzer and organic characterization for natural organic matter removal performance, Chem. Eng. J., 168, 629-634, 2011.

Xiao, F., Huang, J. C. H., Zhang B. J., and Cui, C. W.: Effects of low temperature on coagulation kinetics and floc surface morphology using alum, Desalination, 237, 201-213, 2009.

Zoubolis, A. I. and Tzoupanos, N. D.: Polyaluminium silicate chloride - A systematic study for the preparation and application of an efficient coagulant for water and wastewater treatment, J. Hazard. Mater., 162, 1379-1389, 2009.

Zoubolis, A. I. and Tzoupanos, N. D.: Alternative cost-effective preparation methods of polyaluminium chloride (PAC) coagulation agent: Characterization and comparative application for water/wastewater, Desalination, 250, 339-344, 2010. 